\title{
The effect of surgery (Ovariohysterectomy) on the plasma disposition of meloxicam following intravenous administration in dogs
}

\author{
Umit Karademir ${ }^{1}$, Dilek Aksit ${ }^{2}$, Cavit Kum ${ }^{1}$, Hasan Erdogan ${ }^{3}$, Eyup Hakan Ucar ${ }^{4}$, Cevdet Peker ${ }^{4}$
} and Cengiz Gokbulut ${ }^{5 *}$ (D)

\begin{abstract}
Background: Meloxicam (MLX) is a nonsteroidal anti-inflammatory drug used in the relief of postoperative pain for human and veterinary medicine. This study was designed to investigate the effect of surgery on the plasma disposition of MLX in dogs undergoing ovariohysterectomy following a single intravenous injection at a dose of $0.2 \mathrm{mg} / \mathrm{kg}$ bodyweight. Eight crossbred bitches were used in the study. A two-phase experimental design with a 10-day washout period was used. Pre-operative MLX was administered intravenously to 8 bitches about 10 days before surgery (Phase I, control) at a dose of $0.2 \mathrm{mg} / \mathrm{kg}$ bodyweight and peri-operative MLX was administered intravenously after anaesthesia and 15 min before the start of surgery (Phase II). Blood samples were collected from all animals at various times between 1 and $96 \mathrm{~h}$ after the drug administrations in both phases. The drug concentrations were analysed using high performance liquid chromatography.
\end{abstract}

Results: The volume of plasma MLX distribution at steady-state $\left(\mathrm{Vd}_{\mathrm{ss}}\right)$ of the control group $\left(\mathrm{Vd}_{\mathrm{ss}}: 263.0 \mathrm{ml} / \mathrm{kg}\right)$ was significantly greater $(P<0.05)$ compared to that of the surgery group $\left(V_{\mathrm{ss}}: 149.3 \mathrm{ml} / \mathrm{kg}\right)$. The AUC values were higher $\left(29.5\right.$ vs. $\left.23.0 \mu \mathrm{g} . \mathrm{h}^{2} / \mathrm{ml}\right)$ and the $\mathrm{CL}$ values were lower $(7.7 \mathrm{vs} .10 .5 \mathrm{ml} . \mathrm{h} / \mathrm{kg})$ in the surgery group compared to the control group, respectively, but differences were not significant.

Conclusions: The results of the present study indicated that surgery could alter the plasma disposition of MLX and thus the drug efficacy and side effects such as gastrointestinal ulceration, unusual bleeding and loss of kidney function/failure when repeated doses are used.

Keywords: Dog, Meloxicam, Pharmacokinetics, Surgery

\section{Background}

Analgesic drugs including nonsteroidal anti-inflammatory drugs (NSAIDs), opioids and local anaesthetic agents are used in dogs as peri- and post-surgery pain relievers. NSAIDs are used in veterinary medicine for treating especially musculo-skeletal and abdominal pain [7]. These drugs have antipyretic, anti-inflammatory and analgesic properties. The common mechanism of action for this class of drugs can be attributed to a blockade of the

\footnotetext{
* Correspondence: cengizgokbulut@yahoo.com

${ }^{5}$ Department of Medical Pharmacology, Faculty of Medicine, Balikesir

University, Balikesir, Turkey

Full list of author information is available at the end of the article
}

biosynthesis of prostaglandins, resulting from the inhibitionof enzyme cyclooxygenase (COX) [3, 21].

Meloxicam (MLX), belongs to the enolic acid class of NSAIDs and is also effective as antipyretic, analgesic or anti-inflammatory agent [20]. It preferentially inhibits COX-2, which is induced by inflammatory stimuli in pathophysiological conditions [9]. MLX is about 12 times more potent at inhibiting COX-2 than COX-1 activity [17].

Surgery is a duration when there are some major stresses associated with pain, cardiovascular and possibly major haemodynamic changes peri- and post-operation, especially if there is a significant blood loss [1]. In general, 
the pharmacokinetics of drugs in most species have been characterized in healthy animals. However, the plasma disposition of the active compound and its metabolites may be markedly altered in diseased animals or during peri- or post-operative period.

The pharmacokinetics data are available for some NSAIDs in dogs undergoing surgery and can be compared with other published data $[6,7,11,27]$. However, to the best of our knowledge, this is the first study in which the pharmacokinetic disposition of an NSAID in dogs has been evaluated in the same animal with and without surgery. Our hypothesis was that surgery alters the plasma disposition of certain drugs including analgesics and anaesthetics administered pre- or perioperatively. Therefore, this study was designed to investigate the effects of surgery on the plasma disposition of MLX in dogs undergoing ovariohysterectomy following a single intravenous injection at $0.2 \mathrm{mg} / \mathrm{kg}$ bodyweight.

\section{Results}

Clinically no adverse effects were observed during and after the MLX administration in dogs. The pre-operative biochemical and haematological parameters were within the normal ranges. Mean age, bodyweight, duration of surgery and the selected surgical variables during anaesthesia are shown in Table 1. The heart rate, respiratory rate and end tidal $\mathrm{CO}_{2}$ values were $122.17 \pm 10.6$ beats/ min, $8.5 \pm 0.9$ breaths $/ \mathrm{min}$ and $42.06 \pm 7.3 \mathrm{mmHg}$ during anaesthesia, respectively. The albumin levels of each dog in the control group were similar to its own post-surgery plasma albumin concentration. In addition, the mean albumin concentration in the control group $(2.43 \pm 0.32 \mathrm{~g} /$ dl) was not significantly different (P: 0.719) compared with that observed in the surgery group $(2.50 \pm 0.23 \mathrm{~g} / \mathrm{dl})$.

The analysis yielded linear regression lines ranging from 0.025 to $10 \mu \mathrm{g} / \mathrm{ml}$ of MLX with a correlation coefficient of 0.999. The limits of detection and quantification of the MLX assay were $0.005 \mu \mathrm{g} / \mathrm{ml}$ and $0.02 \mu \mathrm{g} / \mathrm{ml}$, respectively. The mean recovery was $98.32 \%$ (inter assay

Table 1 Mean $( \pm S D)$ values of general characteristics and selected surgical variables during anaesthesia of eight dogs undergoing ovariohysterectomy

\begin{tabular}{ll}
\hline Characteristic & Mean \pm SD \\
\hline Operation time (min) & $29 \pm 7.9$ \\
Age (year) & $1.4 \pm 0.4$ \\
Bodyweight (kg) & $18.25 \pm 4.4$ \\
Time from MLX injection to start of surgery (min) & $15 \pm 0.0$ \\
Heart rate (per min) & $122.17 \pm 10.6$ \\
Respiration rate (per min) & $8.5 \pm 0.9$ \\
End tidal CO2 (mmHg) & $42.06 \pm 7.3$ \\
Oxyhaemoglobin (\%) & $>98$ \\
\hline
\end{tabular}

$\mathrm{CV}=2.09 \%)$ and the accuracy ranged from $96 \%$ to $103 \%$.

Pharmacokinetic parameters of MLX following intravenous administration $(0.2 \mathrm{mg} / \mathrm{kg})$ are given in Table 2 . Semi logarithmic plot of the mean plasma concentration $v s$. time curves are shown in Fig 1. In additions, the scatter plots of the pharmacokinetic parameters $\left(\mathrm{Vd}_{\mathrm{ss}}, \mathrm{T}_{1 / 2}\right.$, $\mathrm{Cl}$ and $\mathrm{AUC}$ ) in control $v s$. surgery group are presented in Fig. 2.

The differences in most pharmacokinetic parameters between the control and surgery groups were not significant, however, variability was high for each phase. Nevertheless, the terminal half-life $\left(\mathrm{T}_{1 / 2 \lambda z}\right)$ and total body clearance $\left(\mathrm{Cl}_{B}\right)$ values were longer and higher, but the area under the curve (AUC) value was smaller in the control group $\left(\mathrm{T}_{1 / 2 \lambda_{\mathrm{Z}}}: 17.21 \mathrm{~h}, \mathrm{Cl}_{\mathrm{B}}: 10.50 \mathrm{ml} . \mathrm{h} / \mathrm{kg}\right.$ and AUC: $23.00 \mu \mathrm{g} . \mathrm{h} / \mathrm{ml}$ ) compared to the surgery

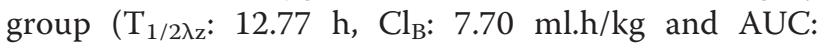
$29.50 \mu \mathrm{g} . \mathrm{h} / \mathrm{ml}$ ), respectively. The volume of MLX distribution at steady-state $\left(\mathrm{Vd}_{\mathrm{ss}}\right)$ of the control group $\left(\mathrm{Vd}_{\mathrm{ss}}\right.$ : $263.00 \mathrm{ml} / \mathrm{kg})$ was significantly larger $(P<0.05)$ compared to that of the surgery group $\left(\mathrm{Vd}_{\mathrm{ss}}: 149.30 \mathrm{ml} / \mathrm{kg}\right)$. The $\mathrm{Vd}_{\mathrm{ss}}$ value of each individual animal decreased in phase I compared with that of the same animals in phase II. Moreover, $\mathrm{T}_{1 / 2 \lambda z}$, AUC and MRT values in 7 out of 8 dogs were altered in the post-surgery group compared to the control group.

\section{Discussion}

The plasma concentration of MLX in dogs following intravenous administration exhibits slight fluctuations, especially in the early hours of the administration in both phases of the present study. Similar observations were also reported by studies performed recently in

Table 2 Median pharmacokinetic parameters with lower and upper confidence intervals of meloxicam in control and surgery groups following intravenous $(0.2 \mathrm{mg} / \mathrm{kg})$ administration to bitches $(n=8)$

\begin{tabular}{|c|c|c|c|}
\hline Parameters & Control group & Surgery group & $P$ values \\
\hline $\mathrm{T}_{1 / 2 \lambda z}(\mathrm{~h})$ & $17.21(12.8-40.1)$ & $12.77(9.8-24.3)$ & 0.289 \\
\hline$C_{0}(\mu \mathrm{g} / \mathrm{m})$ & $1.05(0.7-9.92)$ & $5.3(1.9-14.2)$ & 0.298 \\
\hline $\mathrm{A} \cup C_{\text {last }}(\mu \mathrm{g} \cdot \mathrm{h} / \mathrm{m} /)$ & $21.2(10.8-30.8)$ & $28.5(18.7-45.6)$ & 0.176 \\
\hline$A \cup C_{0 \rightarrow \infty}(\mu \mathrm{g} \cdot \mathrm{h} / \mathrm{m} /)$ & $23.0(12.4-41.0)$ & $29.5(19.4-51.5)$ & 0.322 \\
\hline$A \cup M C_{0 \rightarrow \infty}\left(\mu \mathrm{g} \cdot h^{2} / \mathrm{m} /\right)$ & $698(378-2815)$ & $588(329-2150)$ & 0.959 \\
\hline $\mathrm{Cl}_{B}(\mathrm{~m} / \mathrm{h} / \mathrm{kg})$ & $10.5(6.0-20.6)$ & $7.7(4.9-11.35)$ & 0.191 \\
\hline$V d_{s s}(m / / k g)$ & $263.0(211-470)$ & $149.3(122.4-172.7)$ & $0.016^{*}$ \\
\hline $\mathrm{MRT}_{0 \rightarrow \infty}(\mathrm{h})$ & $28.1(19.5-56.0)$ & $20.7(14.4-34.3)$ & 0.303 \\
\hline
\end{tabular}

$\mathrm{C}_{0}$ : plasma concentration at time $0, \mathrm{AUC}_{0 \rightarrow \infty}$ : area under the (zero moment) curve from time 0 to infinity, $\mathrm{T}_{1 / 2 \lambda z}$ : terminal half-life, $\mathrm{AUMC}_{0 \rightarrow \infty}$ : area under the moment curve from time 0 to infinity; $\mathrm{Cl}_{B}$ : total body clearance of drug; $\mathrm{Vd}_{\mathrm{ss}}$ : volume of distribution at steady-state; $\mathrm{MRT}_{0 \rightarrow \infty}$ : mean residence time *The kinetic parameters in control group are significantly different $(P<0.05)$ from the surgery group 


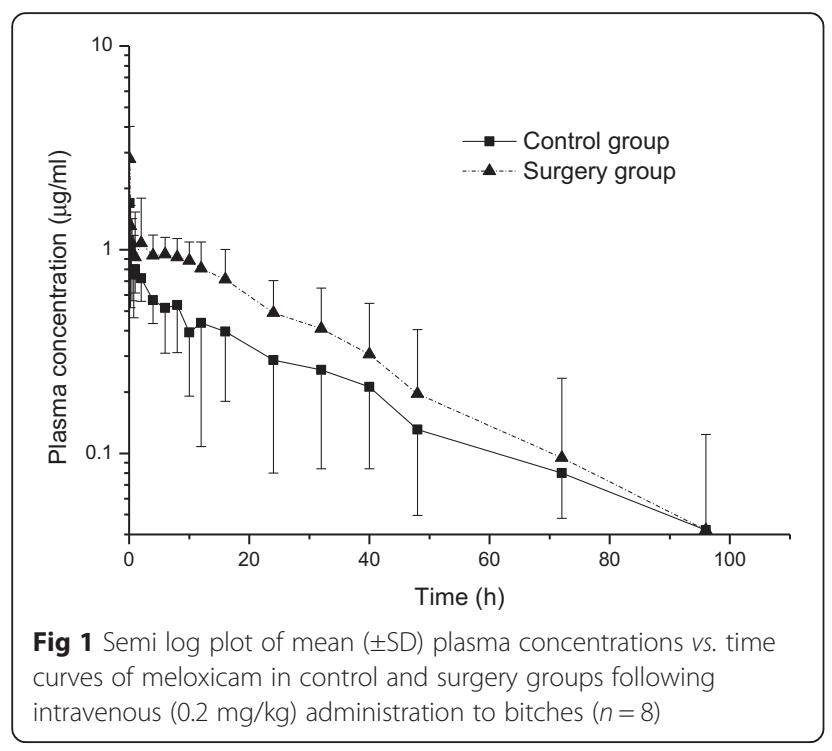

dogs, cats and horses subjected to ketorolac treatment $[7,11,27]$. The reason of such characteristics in plasma concentrations is not clear and probably not associated with the anaesthetic agents and surgical procedures employed in the experiments, since similar fluctuations were observed in the animals of the control group.

There is a reasonable body of literature evaluating perior post-operative analgesic effects and plasma dispositions of some NSAIDs in dogs undergoing surgery $[4,7,8,12$, 24]. However, to our knowledge this is the first study in which the pharmacokinetics of an NSAID in dogs have been evaluated in the same animal with and without surgery. Although, all animals under surgery receive at least 1 drug during the operation for pre-anesthetic medication, anesthesia or analgesia in the surgery unit, there is no information available on the alterations in drug disposition following surgery in veterinary medicine. During the surgery, many hemodynamic and metabolic alterations such as fluctuating hemodynamics, alteration of protein catabolism and anabolism may occur.
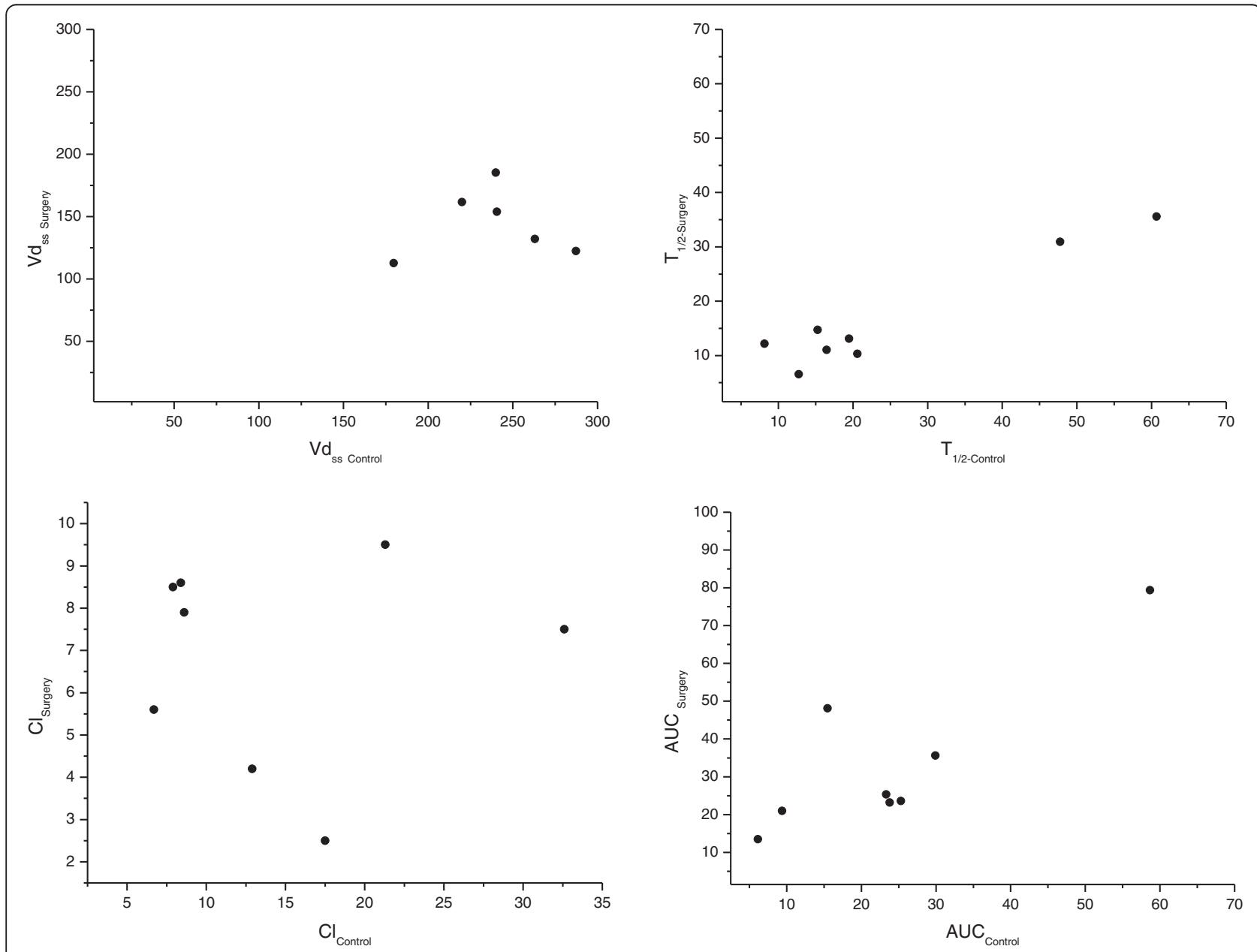

Fig 2 The scatter plots of some pharmacokinetic parameters $\left(\mathrm{Vd}_{5 \mathrm{~s},} \mathrm{~T}_{1 / 2}, \mathrm{Cl}\right.$ and $\left.\mathrm{AUC}\right)$ in control group vs. surgery group following intravenous $(0.2 \mathrm{mg} / \mathrm{kg})$ administration of meloxicam to dogs $(n=8)$ 
The changes in circulation, blood volume, extracellular fluid and blood protein levels, such as $\alpha 1$-acid glycoprotein and albumin may affect the distribution of drugs used during the peri- and post-operative periods [18].

The kinetic parameters of MLX observed from the control group in the present study exhibits a low apparent volume of distribution $(263.00 \mathrm{ml} / \mathrm{kg})$ and a long plasma half-life $(17.21 \mathrm{~h})$ and residence time $(28.10 \mathrm{~h})$ in dogs following the intravenous administration. These findings are in agreement with the results of a previous study [5], regarding the values of $\mathrm{V}_{\mathrm{ss}}(320 \mathrm{ml} / \mathrm{kg}), \mathrm{T}_{1 / 2}$ $(24.0 \mathrm{~h})$, MRT $(34.8 \mathrm{~h})$ and AUC $(21.5 \mu \mathrm{g} . \mathrm{h} / \mathrm{kg})$ in healthy dogs.

The differences in most pharmacokinetic parameters between the control and surgery groups were not significant, however, variability was high for each phase. The dogs in the control group were demonstrated to have a prolonged half-life (17.21 h vs $12.77 \mathrm{~h})$, smaller AUC $(23.00 \mu \mathrm{g} . \mathrm{h} / \mathrm{ml}$ vs $29.50 \mu \mathrm{g} . \mathrm{h} / \mathrm{ml})$ and greater body clearance $\left(\mathrm{Cl}_{\mathrm{B}}\right)$ (10.50 ml.h $/ \mathrm{kg}$ vs $7.70 \mathrm{ml} . \mathrm{h} / \mathrm{kg}$ ) when compared to themselves in the surgery group. Moreover, the volume of MLX distribution at steady-state in the control group $\left(\mathrm{Vd}_{\mathrm{ss}}: 263.00 \mathrm{ml} / \mathrm{kg}\right)$ was significantly greater than that of the surgery group $\left(\mathrm{Vd}_{\mathrm{ss}}: 149.30 \mathrm{ml} / \mathrm{kg}\right)$. Volume of distribution $\left(\mathrm{Vd}_{\mathrm{ss}}\right)$ is one of the most important parameters for the evaluation of the pharmacokinetic characteristics of the drugs and depends on many factors, including the physicochemical properties of the drug, binding strength of plasma proteins, binding capacity to the other tissues. The reason for low levels of $\mathrm{Vd}_{\mathrm{ss}}$ measured in surgery group is probably associated with major haemodynamic changes during the surgery and/or drug-drug interaction. The hepatic activity increases during the post-operative period. Serum albumin turnover elevates, drug-albumin binding characteristics alter and the level of serum proteins, including albumin decreases dramatically for a period following surgery [18]. In addition, it has been reported that the serum albumin level was significantly reduced in dogs with inflammation compared with the healthy dogs [2]. Besides, high plasma albumin binding of MLX could be altered by the anaesthetic drugs, since it has been reported that the plasma proteins (albumin, globulin) decreases in under isoflurane anaesthesia in flying fox [15]. Both the duration and the intensity of drug action with the free drug concentration being the active compound are affected by the level of protein binding [26]. In these circumstances, the protein binding is influenced, particularly for the drugs which have more than $90 \%$ protein bound [18]. The protein binding ratio of MLX in dogs was reported as $97 \%$ [5] and MLX exhibits a high degree of binding to albumin [16]. Generally, the reduction of plasma protein leads the increase of distribution volume and clearance of drugs via the decrease in the plasma protein bindings. However, the mean albumin concentration in the control group $(2.46 \mathrm{~g} / \mathrm{dl})$ was not significantly different (P: 0.719) compared with that observed in the surgery group $(2.48 \mathrm{~g} / \mathrm{dl})$ in the present study. Consequently, the difference on $\mathrm{Vd}_{\mathrm{ss}}$ of MLX is probably not related to the different plasma albumin level between the control and surgery groups. The reason for lower $\mathrm{Vd}_{\mathrm{ss}}$ in the surgery group was however unclear. It is probably related to the other factors such as drug-drug interaction which may have changed the drug-protein binding capacity in the surgery group since atropine sulphate, propofol and isoflurane were combinely used for premedication and as anaesthesia. Also ovariohysterectomy may have affected reproductive hormones and thus the disposition of the drugs. In addition, the reason for lower $\mathrm{Vd}_{\mathrm{ss}}$ in the surgery group could be, at least in part, due to smaller $\mathrm{Cl}_{\mathrm{B}}$ and MRT as $\mathrm{Vd}_{\mathrm{ss}}=\mathrm{Cl}_{\mathrm{B}} \times \mathrm{MRT}$. Moreover, there was a limitation since the control and surgery phases (I and II) were arranged in a sequence, but not in a crossover fashion. This experimental design may potentially induce a period effect. However, this is judged to be unlikely as a 10-day washout period was considered to be sufficiently long [22].

In the present study, the effect of surgical operation on the plasma disposition of MLX was investigated in only crossbred and female dogs. However, the plasma disposition of MLX may be different in pure-bred and between male and female dogs. The elimination halflife of naproxen in beagles $\left(\mathrm{T}_{1 / 2}: 35 \mathrm{~h}\right)$ was much shorter [25], compared with that of observed in mongrels $\left(\mathrm{T}_{1 / 2}: 74 \mathrm{~h}\right)$ [13]. This difference probably reflects a breed difference, since it is known that beagles metabolise drugs more rapidly than other breeds [14]. Besides, it has been reported that, female dogs showed lower AUC and elimination $\mathrm{T}_{1 / 2}$ values of MLX, compared with male dogs [5].

\section{Conclusions}

$\mathrm{Vd}_{\mathrm{ss}}$ of MLX in the control group is significantly greater compared to that of the surgery group. Generally limited or lowered distribution may decrease the drug exposure into tissues. However, the consequent reduction in volume of distribution leads to higher plasma concentrations of MLX. Besides, higher plasma concentration of the increased unbound MLX fraction in plasma may increase risk of side effects such as gastrointestinal ulceration, unusual bleeding and loss of kidney function/failure when repeated doses are used. The change in the disposition of some drugs pre-, periand post-operatively administered for pre-medication, anaesthesia or prevention of post-operative infections may result in changing efficacy and/or increasing side effects or toxicity. 


\section{Methods}

\section{Experimental animals}

A total of 8 client-owned, cross-bred bitches, 2-4 years old and weighing $18.25 \pm 4.4 \mathrm{~kg}$ were used in the study. Animals were judged to be healthy on the basis of physical examinations and haematological and biochemical blood tests. All animals were housed in single boxes and each dog was identified by natural markings. Water was supplied ad libitum and animals were fed a standard commercial diet twice daily with an appropriate quantity of feed during the experimental period. The animals were acclimated for 5 days before the study and food was withdrawn $12 \mathrm{~h}$ before the drug administrations in pre- and peri- surgery.

The study was designed as a two-phase trial with a 10day washout period as this time duration was reported to be adequate for ensuring the clearance of the drug in dogs [22]. A bolus of MLX was administered intravenously to each dog about 10 days before the surgery (Phase I, control) at a dose of $0.2 \mathrm{mg} / \mathrm{kg}$ bodyweight and peri-operative MLX was administered intravenously after the anaesthesia and $15 \mathrm{~min}$ before the start of the surgery (ovariohysterectomy) (Phase II) at the same dose $0.2 \mathrm{mg} / \mathrm{kg}$ bodyweight. MLX administration and blood sampling were performed through the different cephalic veins of each dog. All animals were enrolled after written consent of the owners. The experimenters were blinded to the pharmacological treatment, while processing data and making exclusion decisions. All procedures were carried out under a protocol approved by the Animal Ethics Committee of Adnan Menderes University (Reference number: 64583101/2014/170). All sections of this paper adheres to the ARRIVE Guidelines for reporting animal research [19].

\section{Pre-surgical and surgical procedures}

All dogs in phase II were administered to the following anaesthetic protocol: premedication by subcutaneous atropine sulphate $(0.045 \mathrm{mg} / \mathrm{kg}$ but, Teknovet Atropine; Teknovet, Turkey), induction by intravenous bolus of propofol (4 mg/kg bwt, Propofol $1 \%$; Fresenius, Fresenius Kabi) administered for inducing the anaesthesia. After intubation, the anaesthesia was maintained with isoflurane (Isoflurane USP; Adeka, Turkey). Different levels of isoflurane were used during anaesthesia, to maintain an appropriate depth of anaesthesia based on clinical assessment; heart rate (HR), invasive blood pressure (IBP), muscle relaxation, the degree of nystagmus and response to the surgery were monitored.

MLX (Bavet Meloxicam; Bavet, Istanbul-Turkey) was administered intravenously as a bolus at a dose of $0.2 \mathrm{mg} /$ $\mathrm{kg}$ bodyweight after intubation and $15 \mathrm{~min}$ before the start of the surgery.
After the dog was anesthetized, a standard aseptic preparation was performed, which was followed by elective ovariohysterectomy via a routine ventral midline approach. Same surgeon performed all ovariohysterectomy operations. Respiration rate, $\mathrm{HR}, \mathrm{IBP}, \mathrm{EtCO}_{2}$, oxyhaemoglobin saturation, electrocardiography (lead II), and body temperature were recorded every $5 \mathrm{~min}$ during the operation period using an Utech monitor (VS2000V Vital Signs Monitor; Utech Co. Ltd., China).

\section{Sample collection}

Heparinized blood samples $(3 \mathrm{ml})$ were collected by cephalic venepuncture using a $20 \mathrm{G}$ catheter (B\&D Medical Systems; Istanbul, Turkey) prior to drug administration $(0 \mathrm{~h}), 5,15,30,45 \mathrm{~min}$ and $1,2,4,6,8,10,12$, $16,24,32,40,48,72$ and $96 \mathrm{~h}$ after the administration of MLX. Blood samples were centrifuged at $3000 \mathrm{~g}$ for $20 \mathrm{~min}$ and plasma was transferred to plastic tubes (5 ml). Heparinized drug-free blood samples for analytical method development and validation process were collected from other dogs not included in the study. All the plasma samples were stored at $-20{ }^{\circ} \mathrm{C}$ until the estimations of drug concentrations.

\section{Analytical procedures}

The parent compounds of MLX in dog plasma were analysed using validated high performance liquid chromatography (HPLC) following a liquid-liquid phase extraction procedure. Plasma concentrations of MLX were measured by minor modifications of the methods described by Eniko et al. [10].

Stock solution $(100 \mu \mathrm{g} / \mathrm{ml})$ of pure standard of MLX (Dr. Reddy's Laboratory, India) was first prepared using acetonitrile: water (20:80) as solvent. The resulting stock was then further diluted to produce $0.05,0.5,1,2.5,5$ and $10 \mu \mathrm{g} / \mathrm{ml}$ solutions for calibration as standard curves and to add to the drug-free plasma samples to determine the recovery.

The mobile phase consisted of acetonitrile : $1 \%$ aqueous glacial acetic acid (40:60, v/v) and was delivered (Agilent 1260 Series binary pump; Waldron, Germany) at a flow rate of $1.2 \mathrm{ml} / \mathrm{min}$. An analytical column (Zorbax $\mathrm{CN}$, $5 \mu \mathrm{m}, 4.6 \mathrm{~mm}$ x $250 \mathrm{~mm}$; Agilent Technologies, Wilmington, DE) was used for the analysis of MLX. The eluate was continuously monitored using a photodiode array detector (Agilent 1260 Series Technologies; Waldron, Germany) at a wavelength of $360 \mathrm{~nm}$.

The method for MLX analysis in plasma was validated before the start of the analysis of the study samples. The chromatographic peak of MLX was identified with the retention times of its analytical standard. Recovery of the molecule was determined by comparison of the peak areas from the spiked plasma samples with the areas resulting from direct injections of the analytical reference standard. 
The inter- and intra-assay precisions of the extraction and chromatography procedures were evaluated by processing replicate aliquots of drug-free dog plasma samples containing known amounts of the drug on different days. Calibration graphs were prepared (linear range 0.025$10 \mu \mathrm{g} / \mathrm{ml})$. The slope of the lines between peak areas and drug concentration was determined by least squares linear regression and showed a correlation coefficient between 0.9987 and 0.9999 . The detection limit of the molecule was established with HPLC analysis of blank plasma spiked with the analytical standard and measuring the baseline noise at the peak retention time. The limit of detection (LOD) and limit of quantification (LOQ) were determined for the HPLC method. The limits were determined based on the standard deviation amongst response and slope of the curve at the lowest concentrations.

Plasma albumin concentrations of all samples of each animal were determined by autoanalyser (Sinnowa D280, China), using bromocresol green (Archem A2011, İstanbul, Turkey) as described by Lolekha and Charoenpol [23].

\section{Pharmacokinetics and statistical analysis of data}

The plasma concentration $v s$. time curve obtained after the treatment was fitted with the WinNonlin software program (version 5.2, Pharsight Corp., Mountain View, California, US). The pharmacokinetics parameters for each animal were estimated using non-compartmental model analysis. The trapezoidal rule was used to calculate the area under the plasma concentration time curve (AUC).

The pharmacokinetic parameters are reported as median with lower and upper confidence intervals. The characteristics of dogs (Table 1), the plasma albumin concentrations (Table 2) and the plasma concentrations vs. time curves of MLX (Fig. 1) were expressed as mean \pm SD. The pharmacokinetic parameters and plasma albumin concentrations were statistically compared with a Wilcoxon's signed rank test a nonparametric approach for paired data. All statistical analyses were performed by using MINITAB for Windows (release 12.1, Minitab Inc., State College, PA, USA). Mean values were considered significantly different at $P<0.05$.

\section{Abbreviations \\ $\mathrm{AUC}_{0 \rightarrow \infty}$ : area under the (zero moment) curve from time 0 to infinity; $\mathrm{AUMC}_{0 \rightarrow \infty}$ : area under the moment curve from time 0 to infinity; $\mathrm{C}_{0}$ : plasma concentration at time $0 ; \mathrm{Cl}_{B}$ : total body clearance of drug; \\ COX: cyclooxygenase; $M L X:$ meloxicam; $M_{R T} \rightarrow \infty$ : mean residence time; NSAIDs: nonsteroidal anti-inflammatory drugs; $T_{1 / 2 \lambda z}$ : terminal half-life; $\mathrm{Vd}_{\mathrm{ss}}$ : volume of distribution at steady-state.}

\section{Competing interests}

The authors declare that they have no competing interests.

\section{Authors' contributions}

All authors have made substantial contributions to all of the following: the conception and design of the study (UK, CG), the animal phase of the experiments (UK, CK, HE, EHU, CP), the analytical phase of the study (CG, DA), drafting the article (CG, UK). All authors have read and approved the final manuscript.

\section{Acknowledgements}

The authors would like to thank Prof Hayrettin Cetin for his expert advice with the experimental procedures carried out during the study and Prof. Mehmet Bilgen for proof reading and commenting on the work.

\section{Author details}

${ }^{1}$ Department of Pharmacology and Toxicology, Faculty of Veterinary Medicine, University of Adnan Menderes, Isikli Koyu, Aydin, Turkey. ${ }^{2}$ Department of Pharmacology and Toxicology, Faculty of Veterinary Medicine, Balikesir University, Balikesir, Turkey. ${ }^{3}$ Department of Internal Medicine, Faculty of Veterinary Medicine, University of Adnan Menderes, Isikli Koyu, Aydin, Turkey. ${ }^{4}$ Department of Obstetrics and Gynecology, Faculty of Veterinary Medicine, University of Adnan Menderes, Isikli Koyu, Aydin, Turkey. ${ }^{5}$ Department of Medical Pharmacology, Faculty of Medicine, Balikesir University, Balikesir, Turkey.

Received: 23 October 2015 Accepted: 15 February 2016

Published online: 20 February 2016

\section{References}

1. Barker SJ, Gamel DM, Tremper KK. Cardiovascular effects of anaesthesia and operation. Crit Care Clin. 1987;3:251-68.

2. Belpaire FM, De Rick A, Dello C, Fraeyman N, Bogaert MG. Alpha 1-acid glycoprotein and serum binding of drugs in healthy and diseased dogs. J Vet Pharm Ther. 1984;10:43-8.

3. Botting RM. Cyclooxygenase: Past, present and future. A tribute to John R. Vane (1927-2004). J Therm Biol. 2006:31:208-19.

4. Budsberg SC, Cross AR, Quandt JE, Pablo LS, Runk AR. Evaluation of intravenous administration of meloxicam for perioperative pain management following stifle joint surgery in dogs. Am J Vet Res. 2002;63:1557-63.

5. Busch U, Schmid J, Heinze G, Schmaus H, Baier J, Huber C, et al. Pharmacokinetics of meloxicam in animals and the relevance to humans. Drug Metab Dispos. 1998;26:576-84.

6. Cagnardi P, Zonca A, Gallo M, Villa R, Carli S, Beccaglia M, et al. Pharmacokinetics and perioperative efficacy of intravenous ketorolac in dogs. J Vet Pharm Ther. 2013;36:603-8.

7. Cagnardi P, Ferraresi C, Zonca A, Pecile A, Ravasio G, Zani DD, et al. Clinical pharmacokinetics of tramadol and main metabolites in horses undergoing orchiectomy. Vet Quar. 2014:34:143-51.

8. Caulkett N, Read M, Fowler D, Waldner C. A comparison of the analgesic effects of butorphanol with those of meloxicam after elective ovariohysterectomy in dogs. Can Vet J. 2003:44:565-70.

9. Engelhardt G, Homma D, Schlegel K, Utzmann R, Schnitzler C. Meloxicam: a potent inhibitor of adjuvant arthritis in the Lewis rat. Inf Res. 1995;44:548-55.

10. Eniko C, Ibolya F, Daniela-Lucia M. Development of a HPLC-UV method for determination of meloxicam in human plasma and pharmaceutical dosage forms. Acta Med. 2014;60:142-5.

11. Ferraresi C, Villa R, Ravasio G, Zonca A, Carli S, Pecile A, et al. Pharmacokinetics of IV Ketorolac in Horses Undergoing Orchiectomy. J Equine Vet Sci. 2014:34:870-5.

12. Fowler D, Isakow K, Caulkett N, Waldner C. An evaluation of the analgesic effects of meloxicam in addition to epidural morphine/mepivacaine in dogs undergoing cranial cruciate ligament repair. Can Vet J. 2003:44:643-8.

13. Frey $\mathrm{HH}$, Rieh B. Pharmacokinetics of naproxen in the dog. Am J Vet Res. 1981;42:1615-7.

14. Frey $\mathrm{HH}$, Loscher W. Pharmacokinetics of antiepileptic drugs in the dog: A review. J Vet Pharm Ther. 1985;8:219-33.

15. Heard DJ, Huft VJ. The effect of short term physical restraint and isoflurane anaesthesia on haematology and plasma biochemistry in the island flying fox (Pteropus hypomelanus). J Zoo Wild An. 1998:29:14-7.

16. Jolliet P, Simon N, Brée F, Urien S, Pagliara A, Carrupt PA, et al. Blood-to-brain transfer of various oxicams: effects of plasma binding on their brain delivery. Pharm Res. 1997:14:650-6.

17. Kay-Mugford P, Benn SJ, Lamarre J, Conlon P. In vitro effects of nonsteroidal anti-inflammatory drugs on cyclooxygenase activity in dogs. Am J Vet Res. 2000;61:802-10.

18. Kennedy JM, Riji AM. Effects of surgery on the pharmacokinetic parameters of drugs. Clin Pharm. 1998;35:293-312. 
19. Kilkenny C, Browne WJ, Cuthill IC, Emerson M, Altman DG. Improving bioscience research reporting: the arrive guidelines for reporting animal research. Plos Biology. 2010;8:1-5.

20. Kum C, Voyvoda H, Sekkin S, Karademir U, Tarimcilar T. Effect of carprofen and meloxicam on C-reactive protein, ceruloplasmin and fibrinogen concentrations in dogs undergoing ovariohysterectomy. Am J Vet Res. 2013; 74:1267-73.

21. Lees P, Giraudel J, Landoni MF, Toutain PL. PK-PD integration and PK-PD modelling of nonsteroidal anti-inflammatory drugs: principles and applications in veterinary pharmacology. J Vet Pharm Ther. 2004;27:491-502.

22. Lees P, Landoni MF, Giraudel J, Toutain PL. Pharmacodynamics and pharmacokinetics of nonsteroidal anti-inflammatory drugs in species of veterinary interest. J Vet Pharm Ther. 2004;27:479-90.

23. Lolekha PH, Charoenpol W. Improved automated method for determining serum albumin with bromcresol green. Clin Chem. 1974;20:617-9.

24. Mathews KA, Pettifer G, Foster R, Mcdonell W. Safety and efficacy of preoperative administration of meloxicam, compared with that of ketoprofen and butorphanol in dogs undergoing abdominal surgery. Am J Vet Res. 2001;62:882-8.

25. Runkel R, Forchielli E, Boosz G, Chaplin M, Hill R, Sevelius H, et al. Naproxen metabolism, excretion and comparative pharmacokinetics. Scan J Rheum. 1973;2:24-36.

26. Van Dalen R, Vree TB. Pharmacokinetics of antibiotics in critically ill patients. Intens Care Med. 1990;16:235-8.

27. Villa R, Ravasio G, Ferraresi C, Zonca A, Carli S, Borghi L, et al. Pharmacokinetics of intravenous ketorolac in cats undergoing gonadectomy. N Z Vet J. 2015;63:162-6.

\section{Submit your next manuscript to BioMed Central and we will help you at every step:}

- We accept pre-submission inquiries

- Our selector tool helps you to find the most relevant journal

- We provide round the clock customer support

- Convenient online submission

- Thorough peer review

- Inclusion in PubMed and all major indexing services

- Maximum visibility for your research

Submit your manuscript at www.biomedcentral.com/submit
Biomed Central 